\title{
ЕКСПЕРИМЕНТАЛЬНІ АОСЛІАЖЕННЯ
}

\section{МОРФОЛОГИЧЕСКИЕ ИЗМЕНЕНИЯ ПЕЧЕНИ ПРИ ЭКСПЕРИМЕНТАЛЬНОЙ ЧАСТИЧНОЙ ОБСТРУКЦИИ ОБЩЕГО ЖЕЛЧНОГО ПРОТОКА}

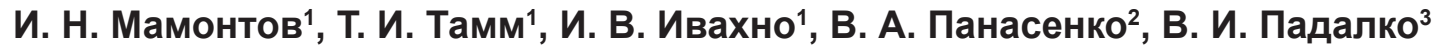 \\ 'Харьковская медицинская академия последипломного образования, \\ ${ }^{2}$ Харьковский национальный медицинский университет, \\ ${ }^{3}$ Харьковский национальный университет имени В. Н. Каразина
}

\section{MORPHOLOGICAL HEPATIC CHANGES IN EXPERIMENTAL PARTIAL OBSTRUCTION OF COMMON BILIARY DUCT}

\author{
I. N. Mamontov', T. I. Tamm¹, I. V. Ivakhno', V. A. Panasenko², V. I. Padalko ${ }^{3}$ \\ ${ }^{1}$ Kharkov Medical Academy of Postgraduate Education, \\ ${ }^{2}$ Kharkov National Medical University, \\ ${ }^{3}$ Kharkov National University named after V. N. Karazin
}

\begin{abstract}
Рефрерат
Цель. Изучить морфологические изменения печени при частичной обструкции (ЧО) общего желчного протока (ОЖП) при повышенном и нормальном уровне билирубина в крови

Материалы и методы. У 36 самцов крыс моделировали полную обструкцию (ПО) ОЖП, у 34 - ЧО ОЖП. Животных выводили из эксперимента через 3, 7, 14, 21, 28 и 35 сут. Определяли содержание билирубина в сыворотке крови, изучали морфологические изменения печени, выполняли морфометрию. В качестве контроля взяты 10 неоперированных и 6 ложно оперированных животных. Результаты. При ПО ОЖП первичные признаки альтерации и воспаления сменялись пролиферацией желчных протоков (ЖП) с постепенным замещением гепатоцитов, их гиперплазией, формированием ложных долек и очагов фриброза. После ЧО ОЖП в различные сроки у животных отмечено повышение уровня билирубина в крови. По сравнению с ПО пролиферация ЖП, как и фиброз, достоверно менее выражены. Изменения в печени при ЧО ОЖП с нормальным уровнем билирубина сопровождались увеличением количества клеток вокругсинусоидных пространств, незначительной пролиферацией ЖП. Гиперплазию гепатоцитов не наблюдали. С 21-х суток определяли начальные проявления фриброза. Нормализация гистоструктуры печени отмечена только при полном восстановлении желчеоттока - при отсутствии расширения ОЖП.

Выводы. При ЧО ОЖП и повышении уровня билирубина в крови изменения печени аналогичны таковым при ПО ОЖП, но достоверно менее выражены, особенно по мере увеличения продолжительности эксперимента. ЧО ОЖП с нормальным содержанием билирубина в крови сопровождалась морфологическими изменениями печени в виде увеличения количества клеток вокругсинусоидных пространств, минимальной пролиферации ЖП, с 21-х суток - слабо выраженными признаками фиброза. Нормальная гистоструктура печени отмечена только у животных при нерасширенном ОЖП.
\end{abstract}

Ключевые слова: частичная обструкция общего желчного протока; холестаз; морфологические изменения печени; эксперимент. Abstract

Objective. To study morphological changes in the liver in partial obstruction of common biliary duct (CBD) while raised and normal level of bilirubin in the blood.

Materials and methods. In 36 male rats a complete obstruction of CBD was simulated, and in 34 - partial obstruction of CBD. Laboratory animals were removed from experiment in $3,7,14,21,28$ and 35 days. Bilirubin content in the blood serum was determined, morphological hepatic changes were studied, and morphometry was conducted. Control group consisted of 10 nonoperated and of 6 falsely operated laboratory animals.

Results. In complete obstruction of CBD the primary signs of alteration and inflammation were changed into the biliary ducts proliferation with staged replacement of hepatocytes, their hyperplasia, formation of false lobules and fibrotic foci. After partial obstruction of CBD in various terms in laboratory animals the level of the blood bilirubin raising was noted. Comparing with complete obstruction, the biliary ducts proliferation as well as fibrosis are trustworthily less pronounced. Hepatic changes in partial obstruction of CBD with normal level of bilirubin were accompanied by enhancement of the cells quantity aroundsinusoid spaces and nonsignificant of the biliary duct proliferation. The hepatocyte's hyperplasia was not observed. From twenty first day the initial fibrotic signs were revealed. Normalization of hepatic histological structure was noted while complete restoration of biliary outflow and only in absence of dilatation of CBD.

Conclusion. In partial obstruction of $\mathrm{CBD}$ and while raising of the blood bilirubin level the hepatic changes are similar to those in complete obstruction of $\mathrm{CBD}$, but they are trustworthily less severe, peculiarly while the experiment duration enhances. Partial obstruction of CBD with normal content of bilirubin in the blood was accompanied by such morphological hepatic changes as the enhancement of the cells quantity aroundsinusoid spaces, minimal proliferation of biliary duct, and from the twenty first day ahead - with light signs of fibrosis. Normal hepatic histological structure was noted in laboratory animals in nondilated CBD.

Keywords: partial obstruction of common biliary duct; cholestasis; morphological hepatic changes; experiment.

Заболевания внепеченочных ЖП, осложненные нарушением их проходимости, занимают одно из ведущих мест в структуре хирургиче- ской гепатологии [1]. Это определяется значительной частотой осложнений желчнокаменной болезни, хронического панкреатита, опухо- лей периампулярной зоны [2 - 6]. В экспериментальных исследованиях, посвященных ПО ЖП, изучены морфологические изменения пече- 
ни, особенности возникновения осложнений, общее течение заболевания [7 - 10]. Однако, лишь в некоторых из них изучена ЧО ЖП [11 - 13]. В этих исследованиях приведены морфологические изменения печени при ПО и ЧО ЖП в сроки до 1 2 нед, морфологические изменения и течение заболевания в более поздние сроки не изучены. Выявление особенностей патогенеза и морфологических изменений в таких моделях позволило бы установить особенности течения заболеваний внепеченочных ЖП в клинике.

Отсутствуют экспериментальные исследования по изучению течения заболевания и морфологии печени при ЧО ЖП при нормальном уровне билирубина. У некоторых больных выявленное по данным визуализирующих методов исследования (УЗИ, ЭРХПГ, КТ, МРТ) расширение внепеченочных ЖП различной этиологии не сопровождается обтурационной желтухой. В некоторых ситуациях лечебная тактика не определена $[4,14]$. Моделирование ЧО внепеченочных ЖП без гипербилирубинемии в эксперименте позволило бы прояснить некоторые аспекты этого состояния.

Целью исследования было изучение морфологических изменений печени при ЧО ОЖП при повышенном и нормальном уровне билирубина в крови.

\section{МАТЕРИАЛЫ И МЕТОДЫ ИССЛЕДОВАНИЯ}

В эксперименте использовали самцов крыс, масса тела 270 - 310 г, которых содержали в стандартных лабораторных условиях.

Оперативное вмешательство выполняли в соответствии с правилами антисептики под общим обезболиванием. Выполняли верхнюю срединную лапаротомию, моделировали ПО ОЖП путем его перевязки и пересечения между двумя лигатурами (у 36 животных) [8]. ЧО ОЖП воспроизводили согласно модели $[11,13]$, в которой ОЖП перевязывали вместе с инструментом заданного диаметра (у 34 животных). В качестве инструмента использовали стандартные медицинские иглы с наружным диаметром 0,7 - 1,1 мм. У
14 животных использовали иглу 0,8 мм, у 16 - 0,7 мм, у 2 - 1,1 мм. После затягивания лигатуры (капрон 4/0) иглу извлекали, таким образом, диаметр лигатуры был ограничен диаметром иглы.

Контролем были 10 неоперированных и 6 ложно оперированных животных. Животных выводили из эксперимента через 3, 7, 14, 21, 28 и 35 сут, оценивали состояние органов брюшной полости. Критерием ЧО ОЖП было его расширение выше лигатуры с наличием желчи в просвете двенадцатиперстной кишки. Стандартным методом определяли содержание билирубина в сыворотке крови. Забирали печень, фиксировали ее в 10\% растворе нейтрального формалина. Гистологические препараты, изготовленные по стандартной методике, окрашивали гематоксилином и эозином, по ванГизон.

Проводили морфометрический анализ с использованием программы для морфометрических исследований ImageJ.

Пролиферацию ЖП оценивали по их количеству в зонах воротных каналов и их объемной плотности (ОП). Для оценки реакции клеток вокругсинусоидных пространств определяли их количество в заданном поле зрения, равном 5,6 × $10^{4}$ мкм², также регистрировали синусоидно-гепатоцитное число (СГЧ) количество клеток вокругсинусоидных пространств на 1000 гепатоцитов. Для количественной оценки гипертрофии гепатоцитов учитывали их площадь и ядерно-цитоплазматическое соотношение (ЯЦС). Степень фиброза оценивали по системе K. Ishak и соавторов [15]. Учитывали выраженность дистрофических и некротических изменений гепатоцитов, воспалительную инфильтрацию и другие морфологические признаки.

Полученные данные обрабатывали с помощью статистических методов.

Эксперимент проведен в соответствии с требованиями и положениями Европейской конвенции по защите позвоночных животных, используемых для экспериментальных и других научных целей (1986).

\section{РЕЗУЛЬТАТЫ}

Из 36 животных, у которых моделировали ПО ОЖП, в различные сроки эксперимента умерли 11 (30,5\%), пик летальности в последние 2 нед (7 животных). Из 34 животных после ЧО ОЖП умерла 1 (2,9\%) крыса на 2-е сутки после операции.

В группе ЧО ОЖП при использовании игл диаметром 0,7 и 0,8 мм только с 7-х суток отмечали нормальный уровень билирубина и расширение ОЖП (у 3 из 10 животных). В связи с этим у 2 животных использовали иглы большего диаметра 1,1 мм, на 3-и сутки у одной из этих крыс уровень билирубина не превышал нормальный, ОЖП был расширен.

При чО ОЖП выделены животные с повышенным (ЧО ПБ) и нормальным (ЧО НБ) содержанием билирубина.

Уровень билирубина в сыворотке крови в группе контроля составил $(7,4 \pm 1,1)$ мкмоль/л. При ПО ОЖП на 3-и сутки содержание билирубина составило $(246,8 \pm 19,9)$ мкмоль/л, на 7-е сутки - $(185,3 \pm 5,6)$

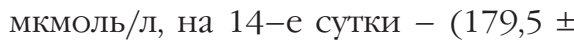
$7,0)$ мкмоль/л, на 21-е сутки - (121,7 $\pm 16,0)$ мкмоль/л, на 28-е сутки $(101,5 \pm 16,6)$ мкмоль/л, на 35-е сутки - $(123,5 \pm 15,5)$ мкмоль/л. При ЧО ПБ уровень билирубина был значительно ниже - через 3, 7, 14, 28 и 35 сут - соответственно $(183,6 \pm 21,0)$, $(131,3 \pm 34,4),(39,5 \pm 13,3), 97$ и 108 мкмоль/л. В группу ЧО НБ включены животные, у которых уровень билирубина не превышал 15 мкмоль/л. При моделировании ЧО ОЖП у одного животного на 21-е сутки и у 2 на 35-е сутки расширение ОЖП не выявлено, уровень билирубина у них был нормальным.

В таблище представлены морфометрические показатели печени животных всех групп, отражающие процессы пролиферации холангиоцитов и ЖП - количество ЖП; фиброзирования - стадию фиброза; замещения паренхимы печени пролиферирующими ЖП - ОП зон воротных каналов; реакцию клеток вокругсинусоидных пространств, прежде всего звездчатых ретикулоэндотелиоцитов - СГЧ; процессы гиперплазии гепатоцитов - ЯЦС. 
Морфометрические показатели печени при по и чО ОЖп

\begin{tabular}{|c|c|c|c|c|c|}
\hline \multirow{2}{*}{$\begin{array}{c}\text { Показатель в группах } \\
\text { животных }\end{array}$} & \multicolumn{5}{|c|}{ Величина показателя ( $\bar{x} \pm$ m) } \\
\hline & $\begin{array}{c}\mathrm{OM}, \\
\mathrm{cm}^{3} / \mathrm{cm}^{3}\end{array}$ & $\begin{array}{c}\text { Количество ЖП, } \\
\text { абс. }\end{array}$ & Стадия фиброза & $\begin{array}{c}\text { СГЧ, ед. } \\
\text { на } 1000 \text { гепатоцитов }\end{array}$ & $\begin{array}{c}\text { ЯЦС, } \\
\text { MKм }^{2} / \mathrm{MKM}^{2}\end{array}$ \\
\hline Контроль (n=10) & $0,01 \pm 0,005$ & $1 \pm 1$ & 0 & $374 \pm 92$ & $0,2 \pm 0,05$ \\
\hline \multicolumn{6}{|l|}{ 3-и сутки } \\
\hline ПО ОЖП $(n=3)$ & $0,063 \pm 0,005$ & $3,6 \pm 0,2$ & 1 & $506 \pm 58$ & $0,39 \pm 0,06$ \\
\hline ЧО ПБ $(n=5)$ & $0,026 \pm 0,01$ & $3,5 \pm 0,8$ & $0-1$ & $561 \pm 91$ & $0,33 \pm 28$ \\
\hline 40 HБ $(n=1)$ & 0,008 & 1 & 0 & 550 & \\
\hline \multicolumn{6}{|l|}{ 7-е сутки } \\
\hline ПО ОЖП $(n=4)$ & $0,076 \pm 0,02 *$ & $12,2 \pm 2,8^{*}$ & $1-2$ & $697 \pm 118$ & $0,47 \pm 0,1^{*}$ \\
\hline ЧО ПБ $(n=7)$ & $0,045 \pm 0,02 *$ & $9,2 \pm 6,0^{*}$ & $0-2$ & $741 \pm 231$ & $0,38 \pm 0,07^{*}$ \\
\hline $4 O$ НБ $(n=3)$ & $0,007 \pm 0,003$ & $1,2 \pm 0,4$ & 0 & $623 \pm 26^{\Delta}$ & $0,24 \pm 0,04$ \\
\hline \multicolumn{6}{|l|}{ 14-е сутки } \\
\hline ПО ОЖП (n=6) & $0,15 \pm 0,04$ & более 20 & $4-5$ & $820 \pm 106$ & $0,5 \pm 0,04$ \\
\hline ЧО ПБ $(n=2)$ & $0,08 \pm 0,02$ & $8,2 \pm 4,3$ & $2-3$ & $928 \pm 119$ & $0,24 \pm 0,007$ \\
\hline 40 НБ $(n=1)$ & 0,015 & 1,3 & 0 & 935 & 0,18 \\
\hline \multicolumn{6}{|l|}{ 21-е сутки } \\
\hline ПО ОЖП $(n=6)$ & $0,27 \pm 0,08^{*}$ & - & $3-4$ & $1134 \pm 194^{*}$ & $0,41 \pm 0,05^{*}$ \\
\hline \multicolumn{6}{|l|}{ ЧО ПБ $(n=0)$} \\
\hline ЧО НБ $(n=4)$ & $0,02 \pm 0,02$ & $1,6 \pm 1,2$ & $0-1$ & $632 \pm 91^{\Delta}$ & $0,17 \pm 0,04$ \\
\hline \multicolumn{6}{|l|}{ 28-е сутки } \\
\hline по ОЖП (n=5) & $0,34 \pm 0,07^{*}$ & - & $3-4$ & $953 \pm 135$ & $0,34 \pm 0,02^{*}$ \\
\hline 40 ПБ $(n=1)$ & 0,068 & 15 & 3 & 817 & 0,33 \\
\hline 40 НБ $(n=2)$ & $0,05 \pm 0,01$ & $10,2 \pm 6$ & $0-2$ & $734 \pm 90$ & $0,19 \pm 0,007$ \\
\hline \multicolumn{6}{|l|}{ 35-е сутки } \\
\hline пО ОЖП (n=2) & $0,39 \pm 0 *$ & - & 4 & $888 \pm 135$ & $0,3 \pm 0 *$ \\
\hline 40 ПБ $(n=1)$ & 0,31 & - & 5 & - & 0,32 \\
\hline ЧО НБ $(n=3)$ & $0,019 \pm 0,018$ & $1,13 \pm 0,28$ & 1 & $646 \pm 172$ & $0,21 \pm 0,02$ \\
\hline
\end{tabular}

Примечание. $\quad$ Различия показателей статистически значимы по сравнению с таковыми: *- в подгуппе ${ }^{40}$ HБ; $^{\Delta}$ - в контроле $(p<0,05)$.

При ПО ОЖП через 3 сут в печени отмечены признаки альтерации и острой воспалительной реакции, наряду с преобладанием пролиферации ЖП, начального фиброза, гиперплазии гепатоцитов. На 7-е сутки количество ЖП увеличилось в 3,4 раза ( $<$ 0,05), прогрессировал фиброз зон воротных каналов. При этом значительно уменьшалась выраженность альтерации и острого воспаления: очаги гепатоцеллюлярного некроза отсутствовали, уменьшалось полнокровие сосудов, исчезал отек межбалочных пространств. На 14-е сутки продолжалось прогрессирование пролиферации холангиоцитов с явлениями фиброзирования и перестройки гистоархитектоники печени. Формировались множественные порто-портальные септы за счет новообразованных холангиоцитов, их предшественниц овальных клеток, что сопровождалось их фиброзированием. Изменения распространялись за пределы зон воротных каналов и септ с образованием ложных долек. На 21е сутки наблюдали дальнейшую перестройку гистоархитектоники печени с полной утратой дольковой структуры. Вытесняющие паренхиму овальные клетки, холангиоциты и сопровождающая их строма с нежной сетью тонких коллагеновых волокон занимали до 42\% общей площади среза. Отмечено некоторое уменьшение гепатоцитов и значительное уменьшение показателя ЯЦС $(\mathrm{p}<0,01)$.

На 28-е и 35-е сутки наблюдали дальнейшее увеличение пролиферации холангиоцитов и их предшественников. Замещение гепатоцитов пролиферирующими ЖП было настолько выражено, что местами отмечали исчезновение паренхимы ложных долек, вместо них гепатоциты располагались отдельными группами и обособленно одни от других. Прослеживалась дальнейшая тенденция к уменьшению ЯЦС.
При ПО ОЖП отмечено увеличение ОП зон воротных каналов во все сроки эксперимента, максимально с 7-х по 21-е сутки. Выраженность фиброза увеличивалась до 14-х суток, наблюдали формирование сливающихся соединительнотканных мостоподобных порто-портальных и порто-центральных септ, нежной сети коллагеновых волокон в зонах пролиферации холангиоцитов, после 14-х суток выраженность фиброза несколько уменьшалась, соединительнотканные волокна были тонкими, едва различимыми, сопровождали новообразованные холангиоциты. СГЧ увеличивалось до $21-$ х суток и уменьшалось на 28-е и 35-е сутки эксперимента. Гиперплазия гепатоцитов прогрессировала до 14-х суток, в последующем - значительно уменьшалась.

При сопоставлении изменений в печени у животных подгруппы ЧО ПБ и группы ПО ОЖП в различные сроки эксперимента мы выявили 
различия морфологических изменений

На 3-и сутки при ЧО ПБ отмечали значительно меньшее расширение зон воротных каналов ( $<<0,05)$, при том же уровне увеличения количества ЖП и начального фиброзирования, менее выраженные некротические изменения паренхимы и незначительно меньшую степень гиперплазии гепатоцитов. На 7-е сутки различия показателей были более выражены. При чО ПБ статистически значимо менышими были показатели ОП зон воротных каналов (р $<0,05)$, количество ЖП в каждом воротном канале ( $<<0,05)$, ЯЦС гепатоцитов ( $<<0,05)$, стадия фиброзирования. На 14-е сутки различия показателей увеличивались: ОП зон воротных каналов и ЯЦС гепатоцитов при ЧО ПБ были в 2 раза меньше, выраженность фиброза - значительно меньше, в виде формирования тонких распространенных порто-портальных септ, что соответствовало фиброзу 2 - 3 стадии, при ПО ОЖП - отмечали фиброз с формированием сливающихся соединительнотканных мостоподобных портопортальных и порто-центральных септ, что соответствовало 4 - 5 стадии фиброза или неполному циррозу печени. При ЧО ПБ ЯЦС и степень гиперплазии гепатоцитов значительно уменьшились, при ПО ОЖП - увеличивались (различия ЯЦС при чО ПБ и ПО ОЖП достоверны, р < 0,05). На 21-е и 28-е сутки при ПО ОЖП продолжалось значительное увеличение выраженности изменений в печени в виде еще большего замещения гепатоцитов холангиоцитами, их предшественниками и стромальными элементами, при чО ПБ на 28-е сутки отмечали незначительное увеличение количества ЖП, фиброз 3 стадии, уменьшение ОП зоны воротных каналов. В полной мере судить об изменениях на 28-е и 35-е сутки при ЧО ПБ не представляется возможным из-за крайне малой выборки - по одному наблюдению.

Рассматривая морфологические изменения печени при ЧО НБ, мы установили, что из всех исследованных показателей только СГЧ и, соответственно, количество клеток во- кругсинусоидных пространств статистически значимо увеличивались по сравнению с таковыми в группе контроля с $7-x$ суток $(\mathrm{p}<0,05)$; отмечена тенденция к увеличению количества ЖП, площади зон воротных каналов и степени фиброзирования - на 21-е сутки. Наблюдали увеличение количества клеток вокругсинусоидных пространств и СГЧ по сравнению с таковыми в группе контроля с 3-х по 35-е сутки, их увеличение на 14-е сутки по сравнению с 7ми и последующее некоторое уменьшение на 21-е и 35-е сутки.

По данным гистологического исследования, в печени животных при нормальном уровне билирубина и нерасширенном ОЖП на 21-е сутки отмечена слабо выраженная стромальная реакция некоторых зон воротных каналов с незначительной мононуклеарной инфильтрацией, ЖП несколько расширены по сравнению с таковыми в группе контроля, количество ЖП и ОП зон воротных каналов не отличались от таковых в норме, фиброз не наблюдали. Количество клеток вокругсинусоидных пространств незначительно превышало таковое в норме. Гиперплазию гепатоцитов не наблюдали; на 35-е сутки строение печени в целом не отличалось от такового в группе контроля.

\section{ОБСУЖДЕНИЕ}

Летальность в группе ПО ОЖП составляла 30,5\% (умерли 11 из 36 животных), однако этот показатель не отражает реальный показатель летальности, поскольку животных выводили из эксперимента поэтапно. Из 8 животных, которых планировали вывести из эксперимента на 35-е сутки, умерли 6 (75\%). Именно такое значение и является реальным при ПО ОЖП длительностью 35 сут.

Высокая летальность является следствием исчерпания компенсаторно-приспособительных процессов, которые на фоне постепенного замещения гепатоцитов пролиферирующими холангиоцитами, ЖП и фиброза, морфологически проявляются признаками атрофии гепатоцитов. Так, с 21-х суток наблюдали значительное уменьшение ЯЦС (p < 0,01), отражающего эти процессы, и именно в этот период отмечен пик летальности при ПО ОЖП.

Поскольку в группе ЧО ОЖП умерла одна крыса из 34, с определенной долей условности можно принять значение 2,9\% показателем летальности при чО ОЖП в сроки наблюдения 35 сут.

Морфологические изменения печени при чО ПБ значительно менее выражены, в целом они отражают наличие тяжелого патологического процесса, обусловленного холестазом. Подобно таковым при ПО ОЖП, пролиферация холангиоцитов и замещение паренхимы печени прогрессировали на протяжении всего периода эксперимента до 35-х суток, но в значительно меньшей степени и без атрофии гепатоцитов. Динамика гипертрофии печеночных клеток была умеренной, что может свидетельствовать об относительной компенсации функций печени.

Морфологические изменения в печени, возникающие при ЧО НБ, отражают реактивную воспалительную реакцию с вовлечением звездчатых ретикулоэндотелиоцитов с минимальным, характерным для холестаза, ответом в виде пролиферации ЖП и минимальной стромальной реакцией зон воротных каналов. Гиперплазию гепатоцитов также не наблюдали, что является косвенным признаком компенсации их функционального состояния. В ходе эксперимента, несмотря на минимальные изменения печени, они усугублялись: увеличивалось количество клеток вокругсинусоидных пространств и пролиферация ЖП, на 21-е сутки выявлены начальные признаки фиброза. Это свидетельствовало, что длительная обструкция внепеченочных ЖП без клинических проявлений в виде желтухи неизбежно обусловливала морфологические изменения печени.

Нормализацию диаметра ОЖП у 3 животных при ЧО ОЖП на 21-е и 35-е сутки следует расценивать как полное восстановление желчеоттока. Это подтверждено данными гистологического исследования - печень этих животных не отличалась от таковой в группе контроля. 
Таким образом, в эксперименте моделирована ЧО ОЖП как с повышением уровня билирубина в крови, так и с его нормальным значением. Морфологические изменения печени, по-видимому, следует сопоставить с функциональными изменениями, что требует проведения дальнейших исследований.

\section{Выводы}

1. При ЧО ОЖП с повышением уровня билирубина в крови изменения печени аналогичны таковым при ПО ОЖП, однако достоверно менее выражены, особенно по мере увеличения продолжительности эксперимента.

2. ЧО ОЖП при нормальном содержании билирубина в крови со- провождалась морфологическими изменениями печени в виде увеличения количества клеток вокругсинусоидных пространств, минимальной пролиферации ЖП, с 21-х суток - признаками слабо выраженного фиброза.

3. Нормальная гистоструктура печени отмечена только у животных при нерасширенном ОЖП.

\section{REFERENCES}

1. Modha K. Clinical approach to patients with obstructive jaundice. Tech Vasc Interv Radiol. 2015 Dec;18(4):197-200. doi: 10.1053/j. tvir.2015.07.002.

2. van Dijk AH, de Reuver PR, Besselink MG, van Laarhoven KJ, Harrison EM, Wigmore SJ, et al. Assessment of available evidence in the management of gallbladder and bile duct stones: a systematic review of international guidelines. HPB (Oxford). 2017 Apr;19(4):297309. doi: 10.1016/j.hpb.2016.12.011.

3. Wilson P, Webster G. Endoscopic management of biliary stone disease. Frontline Gastroenterol. 2017 Apr;8(2):129-32. doi: 10.1136/ flgastro-2016-100786.

4. Saluja SS, Kalayarasan R, Mishra PK, Srivastava S, Chandrasekar S, Godhi S. Chronic pancreatitis with benign biliary obstruction: management issues. World J Surg. 2014 Sep;38(9):2455-9. doi: 10.1007/s00268-014-2581-4.

5. Cauchy F, Regimbeau JM, Fuks D, Balladur P, Tiret E, Paye F. Influence of bile duct obstruction on the results of Frey's procedure for chronic pancreatitis. Pancreatology. 2014 Jan-Feb;14(1):21-6. doi: 10.1016/j.pan.2013.10.008.

6. Boulay BR, Birg A. Malignant biliary obstruction: From palliation to treatment. World J Gastrointest Oncol. 2016 Jun 15;8(6):498-508. doi: 10.4251/wjgo.v8.i6.498.

7. Assimakopoulos SF, Vagianos CE. Bile duct ligation in rats: A reliable model of hepatorenal syndrome? World J Gastroenterol. 2009;15(1):121-3. doi:10.3748/ wjg.15.121.

8. Rodriguez-Garay EA. Cholestasis: human disease and experimental animal models. Annals of Hepatology 2003;2(4): 150-8.

9. Aller MA, Ortega L, Sánchez-Patán F, Anchuelo R, Cruz A, Losada $M$, et al. Microsurgical extrahepatic cholestasis in the rat: A histopathological liver study. The Open Pathology J. 2008;2:71-7. doi: 10.2174/1874375700802010071.

10. Tag CG, Sauer-Lehnen S, Weiskirchen S, et al. Bile duct ligation in mice: induction of inflammatory liver injury and fibrosis by obstructive cholestasis. J Visualized Experiments. 2015;(96):52438:1-11. doi:10.3791/52438.

11. Sekas G. A technique for creating partial obstruction of the common bile duct in the rat. Laboratory Animals. 1990;24:284-7.

12. Rodriguez-Garay EA, Rodriguez GP, Pisani G, Taborda M, Viglianco RA. Reversible cholestasis induced by experimental partial obstruction of the bile duct biochemical, morphometric and hepatic transport kinetic studies. Pathophysiology. 2004;11:7-15. doi: 10.1016/j.pathophys.2003.09.002.

13. Heinrich S, Georgiev P, Weber A, Vergopoulos A, Graf R, Clavien PA. Partial bile duct ligation in mice: A novel model of acute cholestasis. Surgery. 2011;149:445-51.

14. Testoni PA. No treatment for asymptomatic common bile ducts stones? Endosc Int Open. 2017 Nov;5(11):1151-2. doi: 10.1055/s0043-107778.

15. Ishak K, Baptista A, Bianchi L, Callea F, De Groote J, Gudat F, et al. Histological grading and staging of chronic hepatitis. J Hepatol. 1995 Jun;22(6):696-9. 